\title{
Budaya Pembuatan Jubah Bhikkhu Menurut Buddhisme Theravada di Indonesia
}

\author{
Sugianto \\ Sekolah Tinggi Agama Buddha Negeri Sriwijaya Tangerang Banten \\ sugiantovijjayasena@gmail.com.
}

\begin{abstract}
Abstrak
Jubah merupakan kebutuhan utama bagi para bhikkhu. Di Indonesia, bhikkhu Theravada sangat mudah mendapatkan jubah karena banyak umat awam yang sering berdana jubah. Meskipun demikian, upacara pembuatan jubah menurut tradisi Theravada masih tetap dipertahankan. Penelitian ini termasuk jenis deskriptif kualitatif. Obyek penelitian adalah budaya pembuatan jubah dan buddhisme Theravada. Subyek penelitian adalah bhikkhu, pengurus vihara, dan umat awam. Penelitian dilaksanakan di Jakarta, Lembang, dan Tangerang. Waktu penelitian dimulai pada bulan Agustus sampai dengan Desember 2016. Teknik pengumpulan data menggunakan wawancara, dan dokumentasi. Uji keabsahan data dengan uji kredibilitas, dependabilitas, konfirmabilitas, dan transferabilitas hasil penelitian. Analisis data menggunakan model Miles dan Huberman. Hasil penelitian dapat disimpulkan: upacara pembuatan jubah bhikkhu (Kathina Dusam) diselenggarakan setelah akhir masa vassa di vihara yang menjadi tempat vassa lebih dari lima bhikkhu mulai dari pagi sampai malam; upacara pembuatan jubah menghasilkan satu set jubah yang terdiri dari sarung, angsa, jubah dalam, dan jubah luar; proses pembuatan jubah meliputi: upacara penyerahan bahan jubah, pembuatan pola, penjahitan/melipat, mencelub, mengeringkan, dan upacara anumodana; nilainilai yang terkandung dalam kegiatan ini adalah tanggung jawab, bakti, kedermawanan, keyakinan, kebahagiaan, perjuangan, dan pendididikan; dan makna upacara pembuatan jubah bhikkhu dalam moment kathina dusam merupakan bentuk pelestarian kebudayaan Buddhis yang di dalamnya terkandung wujud kebudayaan abstrak, aktivitas sosial, dan material.
\end{abstract}

\section{Kata kunci: Budaya, Jubah Bhikkhu, Buddhisme Theravada}

\section{A. Pendahuluan}

Agama Buddha telah lama masuk dan berkembang sejak era Nusantara. Bukti dari eksistensi agama Buddha pada masa itu adalah dengan ditemukan berbagai peninggalan sejarah yang bercorak Buddhis berupa candi, sastra, maupun berita. Pada masa sekarang, aliran yang berkembang di Indonesia seperti Mahayana, Theravada, Buddhayana, Tridharma, NSI, Tantrayana, Maitreya.

Pakaian keagamaan merupakan identitas yang paling mudah dikenali di antara aliran Buddhisme. Jubah adalah pakaian keagamaan dan kebutuhan pokok 
bhikkhu atau samanera. Ada beragam bentuk, warna, ukuran, dan model jubah. Untuk memperoleh jubah, bhikkhu menerima persembahan umat atau membuat jubah. Beberapa bhikkhu yang tergabung dalam organisasi Sangha Theravada Indonesia masih memelihara tradisi pembuatan jubah bhikkhu. Vihara Jakarta Dhammacakka Jaya di Sunter, Jakarta Utara menjadi tempat rutin penyelenggaraan upacara pembuatan jubah oleh para bhikkhu.

Berdasarkan latar belakang di atas, permasalahan-permasalahan penelitian diidentifikasi sebagai berikut: (1) Upacara pembuatan jubah bhikkhu menurut tradisi Buddhisme Theravada belum bisa dilaksanakan di semua vihara di Indonesia; (2) Tidak semua bhikkhu memiliki kesempatan melaksanakan upacara pembuatan jubah bhikkhu; (3) Belum banyak umat Buddha yang memiliki kesempatan untuk berpartisipasi dalam upacara pembuatan jubah bhikkhu; dan (4) Kurangnya pemahaman terhadap proses dan nilai-nilai yang terkandung dalam upacara pembuatan jubah bhikkhu menurut buddhisme Theravada.

Rumusan masalah penelitian ini adalah bagaimanakah proses dan nilai-nilai serta makna yang terkandung dalam upacara pembuatan jubah bhikkhu menurut buddhisme Theravada? Tujuan dari penelitian ini adalah menjelaskan proses dan nilai-nilai serta makna yang terkandung dalam upacara pembuatan jubah bhikkhu menurut buddhisme Theravada.

1. Pengertian Kebudayaan

Menurut bahasa Sansekerta, kebudayaan disebut Buddhayah, bentuk jamak dari kata buddhi yang berarti budi atau akal (Soekanto, 2007: 150). Selo Menurut Selo Sumardjan dan Soelaeman Soemardi dalam Soekanto (2007: 151) semua kebudayaan merupakan hasil karya, rasa, dan cipta masyarakat. Kebudayaan merupakan kebudayaan berhubungan dengan sesuatu yang positif atau baik yang dihasilkan oleh cipta, rasa dan karya. Kebudayaan Buddhis merupakan bentuk budaya yang dipengaruhi oleh nilai-nilai ajaran Buddha dalam bentuk abstrak maupun konkrit.

Kebudayaan merupakan sesuatu yang kompleks. J. J. Honigmann (dalam Koenjtaraningrat, 2000) membedakan adanya tiga 'gejala kebudayaan': yaitu : (1) ideas, (2) activities, dan (3) artifact. Berdasarkan tiga gejala tersebut diperjelas oleh Koenjtaraningrat dengan cara memberikan istilah sebagai tiga wujud kebudayaan yaitu (1) Suatu yang kompleks dari ide-ide, gagasan-gagasan, nilai-nilai, norma-norma, peraturan dan sebagainya; (2) Suatu kompleks aktivitas serta tindakan berpola dari manusia dalam masyarakat; dan (3) Benda-benda hasil karya manusia.

Jubah bhikkhu merupakan contoh bentuk kebudayaan Buddhis yang berupa benda. Jubah merupakan salah satu persyaratan yang harus dimiliki oleh sesorang samanera yang akan diupasampada menjadi bhikkhu. Untuk dapat diupasampada atau ditabhis menjadi bhikkhu, seorang samanera harus memiliki satu set jubah lengkap. 
Jumlah jubah pada mulanya ada dua yaitu kain untuk ikat pinggang (seperti sarung) dan jubah untuk bagian atas. salah satu kegunaan jubah dipakai bhikkhu untuk menerima persembahan dana makanan dari umat. Pada perkembangan selanjutnya, jubah yang dimiliki bhikkhu jumlahnya bertambah menjadi tiga sehingga disebut ticivaram. Pada jaman Buddha, sanghati merupakan jubah tambahan yang digunakan selama musim dingin. Sanghati merupakan kain jubah yang digunakan pada musim dingin atau dipakai pada bagian luar. Uttarasanga adalah jubah yang dipakai di bagian bawah. antaravasaka merupakan jubah yang dikenakan untuk membalut tubuh bagian bawah (Vajirananvaronasa, 1983).

Ada enam jenis kain yang dapat digunakan sebagai bahan pembuatan jubah, yaitu: kain yang terbuat dari serat tanaman, kain yang terbuat dari katun, kain yang terbuat dari benang sutera, kain yang terbuat dari rambut binatang, kecuali rambut manusia atau bulu badan manusia, kain yang terbuat dari benang rami, kain yang terbuat dari campuran. Kain selain yang terbuat dari keenam bahan di atas tidak diperkenankan dipakai (Vajirananvaronasa, 1983).

Jubah dibuat dengan motif sawah Magadha. Panel yang besar disebut mandala, panel yang lebih kecil disebut atthamandala. Ada garis-garis pemisah di tepi bidang yang disebut atthakusi. Antara mandala, atthamandala, dan atthakusi secara bersama-sama disebut khanda atau bagian (Vajirananvaronasa, 1983).

Kain jubah diberi warna dengan menggunakan salah satu dari enam cara yaitu akar dan umbi, tanaman, kulit pohon, daun, bunga, dan buah. Bahan-bahan tersebut dimasukkan ke dalam air dan direbus dalam jangka waktu yang lama. Nama warna yang disebut dalam Pali Teks adalah kasaya atau kasava. Warna seperti indigo, kuning, merah, magenta, scarlet, pink, dan hitam dilarang. Warna yang diijinkan adalah campuran warna kuning dengan merah (Vajirananvaronasa, 1983).

Buddhisme (Crosby, 2013) adalah sebuah istilah yang digunakan untuk nama agama (Buddha) yang penganutnya baik pribadi maupun komunitas menyatakan perlindungan kepada Buddha, Dhamma, dan Sangha. "Buddhism is the term now used for the religion of those individuals and communities that maintain and support the Buddha, Dhamma, and Sangha so that they continue to be available as refuges.

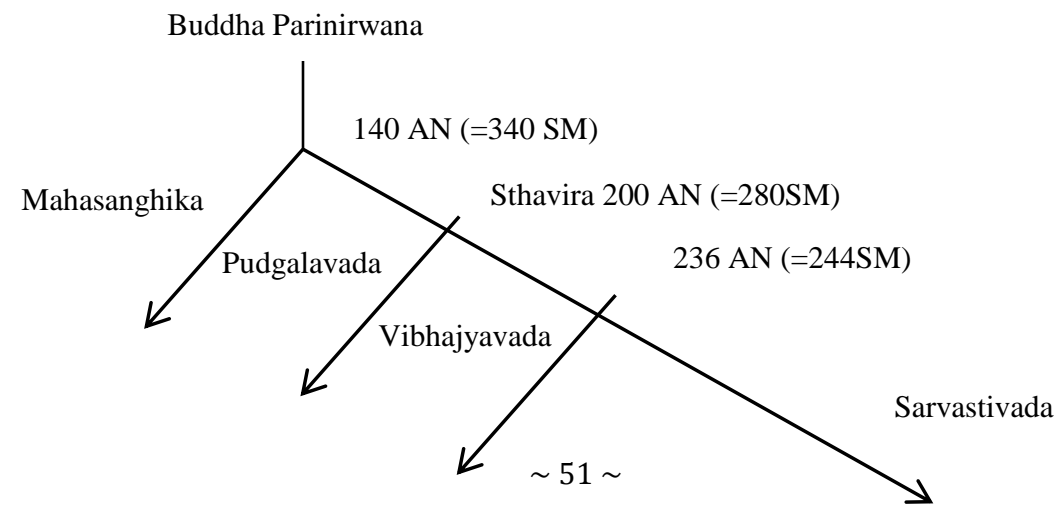


Munculnya Buddhisme Theravada tidak lepas dari aliran-aliran yang muncul jauh sebelum era sekarang. Dari beberapa aliran yang ada pada diagram di atas, Theravada lebih cenderung sesuai dengan aliran Vibhajyavada, aliran yang didukung oleh Raja Asoka. Istilah Theravada muncul pada era modern, yang secara literatur berarti tradisi dari para sesepuh yang diresmikan pada acara World Fellowship of Buddhist tahun 1950 (Conze, 2010).

\section{B. Metodologi Penelitian}

Penelitian dengan judul Budaya Pembuatan Jubah Bhikkhu Menurut Buddhisme Theravada di Indonesia merupakan jenis penelitian deskriptif kualitatif. Creswell dalam Sugiyono (2012) menyatakan bahwa penelitian kualitatif berarti proses eksplorasi dan memahami makna perilaku individu dan kelompok, menggambarkan masalah sosial dan masalah kemanusiaan (Sugiyono, 2013: 228).

Penelitian dilaksanakan di Jakarta dan Lembang. Peneliti mengunjungi viharavihara yang pernah menyelenggarakan upacara pembuatan jubah kathina antara lain Vihara Jakarta Dhammacakka Jaya, dan vihara yang menjadi tempat tinggal bagi bhikkhu yang memiliki pengetahuan tentang jubah bhikkhu Theravada. Waktu penelitian dimulai pada bulan Agustus sampai dengan Desember 2016.

Teknik dan instruman pengumpulan data dengan menggunakan wawancara, dan dokumentasi. Instrumen penelitian berpedoman pada pedoman wawancara, dan alat dokumentasi. Untuk menguji keabsahan data dilakukan dengan uji kredibilitas, dependabilitas, konfirmabilitas, dan transferabilitas hasil penelitian (Sugiyono, 2012: 366). Analisis data menggunakan teknik Miles dan Huberman.

\section{Hasil dan Pembahasan}

Vihara Jakarta Dhammacakka Jaya merupakan vihara beraliran Theravada yang berlokasi di kawasan perumahan Sunter Agung Permai, Jakarta Utara. Pembangunan Vihara Dhammacakka mulai berlangsung sejak tahun 1981. Bhikkhu yang menjadi pemprakarasa dalam pendirian vihara adalah Phragru Dhammadron Sombat.

Vihara Dhammacakka memiliki sarana dan prasarana yang lengkap. Di dalam komplek Vihara Dhammacakka terdiri dari beberapa bangunan yang memiliki fungsi penting, antara lain kuti; dhammasala; uposathagara; perpustakaan, replika candi pawon; plaza pohon Bodhi, kolam teratai; serta Genta dan Tambur. Vihara Dhamacakka memiliki berbagai kegiatan rutin untuk melayani kebutuhan spiritual umat antara lain Kathina dusam yaitu upacara pembuatan jubah bhikkhu setelah selesai masa vassa. 


\section{Bentuk jubah bhikkhu menurut buddhisme Theravada}

Jubah bhikkhu Theravada merupakan lembaran kain yang berwarna kecoklatan. Agar bisa dikenakan oleh bhikkhu, lembaran kain jubah dilipat dan digulung dengan teknik tertentu sehingga menyerupai pakaian. Ukuran jubah bhikkhu Theravada disesuaikan dengan ukuran dan tinggi badan bhikkhu. Bhikkhu dapat menyesuaikan ukuran jubah dengan ukuran badan dengan cara menambah atau mengurangi kain jubah. Jubah yang dikenakan oleh bhikkhu Theravada tidak boleh melebihi atas lutut bhikkhu atau menyentuh tanah.

Kegiatan kathina dusam, membuat jubah satu set yang terdiri dari sarung, angsa, jubah dalam, dan jubah luar. Sarung bhikkhu adalah lembaran kain yang pemakaiannya seperti sarung pada umumnya untuk menutup tubuh bagian bawah. Angsa merupakan selembar kain yang pemakaiannya seperti pakaian dalam atas yang terbuka di sebelah bahu kanan. Jubah dalam merupakan lembaran kain yang ukuran paling besar dibandingkan dengan sarung dan angsa. Jubah dalam dipakai dengan cara digulung untuk menutupi kaki sampai dengan pundak, kadang pundak kanan terbuka atau tertutup keduanya, tergantung keberadaan bhikkhu. Jubah luar atau sanghati merupakan jubah luar yang multifungsi serta memiliki kainnya lebih tebal dibandingkan jubah dalam, karena jubah luar memiliki banyak kegunaan, salah satunya untuk selimut di malam hari atau menutup tubuh saat bhikkhu berada di daerah yang memiliki cuaca sangat dingin.

\section{Proses pembuatan jubah kathina}

Pembuatan jubah setelah akhir vassa menjadi salah satu tradisi yang dipertahankan di Vihara Jakarta Dhammacakka Jaya. Pembuatan jubah kathina untuk bhikkhu Theravada dapat diselenggarkan bila ada minimal 5 bhikkhu yang bervassa dan menyelesaikan vassa dengan baik. Koordinator acara upacara pembuatan jubah pada tahun 2016 memutuskan penyelenggaraan di hari Sabtu setelah beberapa hari masa vassa selesai. Pertimbangan pemilihan hari Sabtu antara lain agar umat yang berpartisipasi dalam kegiatan ini lebih banyak, termasuk anak-anak, karena hari Sabtu pada umumnya sekolah dan kantor libur. Sedangkan pemilihan hari yaitu beberapa hari setelah masa vassa selesai dengan pertimbangan para bhikkhu masih berada di Vihara Dhammacakka, belum sibuk dengan kegiatan Kathina. Lama waktu yang dibutuhkan untuk pembuatan dan penyelesaian jubah bhikkhu ini adalah kurang dari satu hari. Hal ini dimulai dari upacara penyerahan kain bahan jubah dari umat sampai dengan upacara sangha.

Ada beberapa tahapan dalam pembuatan jubah bhikkhu dalam kegiatan kathina dusam. Tahapan-tahapan pembuatan jubah bhikkhu yaitu upacara penyerahan bahan jubah dari umat ke bhikkhu sangha; pembuatan pola; menjahit/melipat; mencelub; mengeringkan jubah; dan upacara sangha. 
Upacara penyerahan kain atau bahan jubah dari umat ke bhikkhu sangha diadakan pada pagi hari, yaitu setelah para bhikkhu selesai makan pagi. Kain yang diserahkan untuk bahan pembuatan jubah adalah kain katun yang belum diwarnai. Pada upacara tersebut, umat atau pewakilan umat terlebih dahulu melakukan penghormatan kepada Tiratana, memohon bimbingan sila, lalu menyerahkan kepada bhikkhu. Setelah itu bhikkhu membacakan paritta. Setelah selesai membacakan paritta, para bhikkhu berunding secara internal untuk membahas bhikkhu yang pantas menerima jubah kathina, dan pembagian tugas dalam proses pembuatan jubah kathina.

Tahap kedua adalah pembuatan pola jubah. Jubah bhikkhu Theravada terdapat pola-pola yang mengacu pada tradisi yang berlaku sejak zaman Buddha Gotama, yaitu berupa petak-petak yang menyerupai sawah di Magadha. Ada petakan yang kecil dan ada juga petakan yang lebar. Proses pembuatan pola dimulai dengan cara kain bahan jubah dibentangkan di atas meja. Lalu digaris sesuai dengan pola yang akan dibuat. Pola-pola tersebut mengacu pada aturanaturan yang ada dalam vinaya. Dengan proses demikian, pola yang dibuat sesuai dengan standar yang sudah ada. Setelah pola jubah selesai dibuat maka selanjutnya dipotong dengan menggunakan gunting kain mengikuti pola.

Tahap ketiga adalah menjahit potongan kain. Pada tahap ini bila bhikkhu memiliki keterampilan dalam menjahit maka pengerjaanya dapat dilakukan oleh bhikkhu. Namun bila tidak ada bhikkhu yang mampu menjahit maka menggunakan jasa tukang jahit profesional yang pengerjaannya dalam pengarahan bhikkhu ataupun koordinator pembuatan jubah. Penjahit akan menyatukan potongan-potongan kain sesuai pola atau melipat kain bahan jubah lalu dijahit sesuai dengan pola jubah bhikkhu yang dibuat. Hasil dari tahap ketiga adalah jubah polos dengan pola yang standar telah dibuat.

Tahap keempat adalah mencelubkan jubah polos ke pewarna. Pewarna yang digunakan untuk mewarnai jubah yang masih polos berasal dari bahan kimia yang dibuat oleh pabrik. Untuk mengasilkan warna yang diiinginkan, dilakukan pencampuran beberapa warna. Proses ini dilakukan dengan cara tepat, bila salah akan menghasilkan warna yang tidak sesuai. Selain itu, ada beberapa hal yang dipertimbangkan antara lain berat kain, jumlah air yang digunakan untuk mencampurkan warna, serta temperatur air. Sebelum jubah dimasukkan, air dimasak di dalam panci besar lalu direbus terlebih dahulu sampai mendidih atau mencapai suhu yang telah ditentukan lalu pewarna dimasukan pewarna lalu diaduk. Setelah warna tercampur menjadi satu maka jubah polos dimasukkan dan diaduk-aduk secara merata. Proses pengadukan membutuhkan keterampilan agar pewarnaan pada kain merata, hingga warna yang diperoleh pada jubah hasilnya bagus.

Tahap kelima adalah mengeringkan jubah. Mengeringkan jubah dilakukan dengan berbagai cara antara lain langsung dijemur atau telebih dahulu dimasukkan ke dalam mesin pengering. Pada zaman sekarang, berkat kemajuan teknologi, proses pengeringan jauh relatif lancar, tidak ada hambatan. Bila cuaca tidak mendukung proses pengeringan karena hujan 
turun, maka dapat menggunakan mesin pengering. Jubah yang telah diwarnai dengan sempurna lalu dijemur ditempat yang terkena sinar matahari atau yang terdapat angin agar cepat kering. Setelah jubah benar-benar kering maka dilipat dengan rapi sebelum diserahkan pada bhikkhu yang pantas menerima jubah kathina di upacara sangha.

Tahap terakhir adalah upacara sangha. Upacara sangha hanya diikuti oleh bhikkhu sangha yang tinggal di vihara tersebut. Umumnya pelaksanaannya malam karena harus menunggu jubah sampai kering dan rapi. Upacara sangha dilakukan sebagai bentuk anumodana atau apresiasi terhadap keberhasilan para bhikkhu dalam menyelesaikan pembuatan jubah. Inti dari kegiatan ini adalah penyerahan jubah kathina oleh sangha kepada salah satu bhikkhu yang pantas menerima. Umumnya bhikkhu yang menerima jubah kathina adalah yang paling senior dalam masa vassa, kepala vihara, bhikkhu yang menabhiskan bhikkhu baru (upajjhaya), atau yang paling memahami patimokha.

3. Kelebihan memiliki jubah kathina bagi bhikkhu

Bagi bhikkhu yang menerima persembahan jubah kathina, dalam penggunaan jubah dan tata cara pemakaiannya sama dengan jubah bhikkhu pada umumnya. Namun bagi bhikkhu yang menerima jubah kathina atau yang berpartisipasi dalam kegiatan pembuatan jubah kathina akan mendapatkan hak istimewa. Hak istimewa tersebut berupa kelonggaran dalam mematuhi aturan kebhikhuan terutama yang berkaitan dengan penggunaan jubah sanghati, antara lain: Bhikkhu yang menerima jubah kathina atau terlibat dalam pembuatan jubah kathina ketika pergi meninggalkan vihara dapat meninggalkan sanghati di vihara atau pergi tanpa membawa sanghati.

4. Nilai-nilai dalam upacara pembuatan jubah bhikkhu

a. Tanggung jawab

Bhikkhu yang menerima persembahan kain bahan jubah dari umat memiliki tanggung jawab untuk membuat dan menyelesaikan pembuatan jubah dalam waktu kurang dari satu hari. Tanggung jawab umat yang berpartisipasi dalam kegiatan pembuatan jubah sesuai dengan pekerjaan yang dilakukan.

b. Bakti

Para bhikkhu menunjukkan rasa bakti dengan menyelenggarakan upacara tersebut. Meskipun kebutuhan jubah saat ini sangat mudah terpenuhi oleh bhikkhu, namun bila syarat penyelenggaraan kathina dusam terpenuhi maka bhikkhu akan membuat jubah sesuai dengan kemampuan dan berdasarkan aturan-aturan yang disesuaikan dengan perkembangan zaman. Sedangkan wujud bakti dari umat awam dengan membantu para bhikkhu yang sedang membuat jubah agar selesai dengan baik dan tepat waktu.

c. Kedermawanan

Umat berdana berupa materi yaitu kain polos untuk membuat jubah. Berdana tenaga untuk membantu proses pengerjaan membuat pola, memotong, melipat, 
menjahit, dan mewarnai jubah. Umat juga berdana waktu dengan meluangkan waktu datang ke vihara. Umat berdana pengetahuan yaitu terkait cara menjahit, mencampur warna. Bhikkhu sangha memiliki kesempatan berdana non-materi kepada umat berupa dhammadana. Mengajarkan kebaikan-kebaikan yang dapat diterapkan umat untuk membantu bhikkhu sangha.

d. Gotong royong/ kerja sama

Pembuatan jubah bhikkhu pada saat kathina dusam tidak dapat dikerjakan oleh satu orang. Ada banyak orang yang terlibat dalam kegiatan tersebut. Bhikkhu sangha dan umat awam berkerja sama agar pembuatan jubah terlaksana dengan baik, tepat waktu, dan berkualitas. Bantuan dari umat awam sangat membantu bhikkhu dalam menyelesaikan pengerjaan pembuatan jubah tepat waktu.

e. Keyakinan

Keyakinan umat bahwa berdana kepada sangha bernilai besar menjadi motivasi mengikuti kegiatan penelitian. Berdana kepada bhikkhu sangha adalah ladang yang subur, artinya siapapun yang telah melakukan kebaikan berupa dana kepada bhikkhu sangha, terutama dalam hal pemenuhan jubah akan mendapat berkah kebahagiaan dalam kehidupan saat ini dan yang akan datang.

f. Kebahagiaan

Umat awam merasa bahagia pada saat menyerahkan dana. Bangga memiliki kesempatan melakukan kebaikan kepada sangha, bisa berdana kebutuhan pokok bhikkhu berupa jubah. Bahagia muncul karena menyadari bahwa penyelenggaraan upacara ini mengacu pada sebuah tradisi yang sudah sangat lama berlangsung yaitu sejak zaman Buddha, serta dengan berdana jubah kathina berarti umat telah mempersembahkan barang bagi sangha. Bhikkhu yang terlibat kegiatan ini pun bahagia karena memiliki kesempatan melaksanakan tradisi yang sudah berlangsung sangat lama. Tidak semua bhikkhu di Indonesia memiliki kesempatan berpartisipasi dalam kegiatan kathina dusam, atau menerima jubah kathina.

\section{g. Perjuangan}

Pembuatan jubah bhikkhu Theravada membutuhkan perjuangan agar selesai tepat waktu dengan hasil yang memuaskan. Umat juga berjuang meluangkan waktu di antara aktivitas-aktivitas yang dijalankan oleh perumah tangga.

h. Pendidikan

Kathina dusam merupakan media untuk mengenalkan kebudayaan Buddhis kepada masyarakat. Bhikkhu dan umat menjadi tahu proses pembuatan jubah bhikkhu yang sesuai aturan vinaya. Meskipun untuk pembuatannya tidak sepenuhnya seperti jaman dahulu. Misalnya penggunaan bingkai yang sudah tidak berlaku lagi dengan tersedianya kain yang melimpah dan alat ukur yang terbukti handal dijadikan alat pengukuran jubah. 


\section{Makna Upacara Pembuatan Jubah Bhikkhu (Kathina dusam)}

Makna dari pelaksanaan upacara pembuatan jubah bhikkhu (kathina dusam) adalah bentuk pelestarian kebudayaan Buddhis. Pembuatan jubah bhikkhu melalui upacara kathina dusam merupakan bentuk pelestarian kebudayaan buddhis di Indonesia. Dalam kegiatan ini terkandung nilai-nilai atau aturan yang dijadikan pedoman penyelenggaraan, serta gagasan-gagasan yang menyebabkan bhikkhu sangha menyelenggarakan upacara tersebut. Selama proses kegiatan berlangsung, aktivitas-aktivitas yang khas dalam pembuatan jubah dapat diamati, baik yang dilakukan oleh bhikkhu sangha maupun oleh umat awam. Upacara kathina dusam menghasilkan karya berupa satu set jubah bhikkhu Theravada yang kemudian dipersembahkan kepada satu bhikkhu yang pantas menerima.

\section{Simpulan}

Berdasarkan hasil penelitian dan pembahsan maka dapat disimpulkan:

1. Upacara pembuatan jubah bhikkhu (Kathina Dusam) diselenggarakan setelah akhir masa vassa di vihara yang menjadi tempat vassa lebih dari lima bhikkhu yang dilaksanakan dari pagi sampai malam (kurang dari satu hari)

2. Upacara pembuatan jubah ini menghasilkan satu set jubah yang terdiri dari sarung, angsa, jubah dalam, dan jubah luar

3. Proses pembuatan jubah meliputi: upacara penyerahan bahan jubah, pembuatan pola, penjahitan/melipat, mencelub, mengeringkan, dan upacara anumodana

4. Nilai-nilai yang terkandung dalam kegiatan ini adalah tanggung jawab, bakti, kedermawanan, keyakinan, kebahagiaan, perjuangan, dan pendididikan

5. Makna upacara pembuatan jubah bhikkhu dalam momen kathina dusam merupakan bentuk pelestarian kebudayaan yang di dalamnya terkandung wujud kebudayaan abstrak, aktivitas sosial, dan material.

\section{Daftar pustaka}

Conze, Edward. 2010. Sejarah Singkat Agama Buddha. Jakarta: Karaniya

Crosby, Kate. 2013. Theravada Buddhism: Continuity, Diversity, and Identity. Wiley: Blackwell.

Koentjaraningrat. 2000. Pengantar Ilmu Antropologi. Jakarta: Rineka Cipta.

Mundandar, Agus Aris. Catuspatha Arkeologi Majapahit. Jakarta: Penerbit Wedatama Widya Sastra.

Sayadaw, Mingun. 2008. Riwayat Agung Para Buddha: The Great Chronicles of Buddhas. Terjemahan: Indra Anggara, Jakarta: Ehipassiko Foundation \& Giri Mangala Publications. 
Sugiyono. 2012. Metode Penelitian Pendidikan Pendekatan Kuantitatif, Kualitatif, dan RED. Bandung: Penerbit Alfa Beta.

Soekanto, Soerjono. 2007. Sosiologi Suatu Pengantar. Jakarta: PT Rajagrafindo Persada.

Utomo, Bambang Budi. Buddha di Nusantara. Surabaya: Buddhist Education Centre.

Vajirananavarorasa, Somdet Phra Maha Samana Chao Krom Phraya. 2000. The Entrance To The Vinaya. Vinayamukha Vol. II. Bangkok: Mahamakut Rajavidyalaya Press.

Vajirananavarorasa, Somdet Phra Maha Samana Chao Krom Phraya. 2000. The Entrance To The Vinaya. Vinayamukha Vol. III. Bangkok: Mahamakut Rajavidyalaya Press.

Webber, Max. 2002. Teori Dasar Analisis Kebudayaan. Jogyakarta: ICRCiSoD. 